\title{
The roles of poly(ADP-ribose)-metabolizing enzymes in alkylation-induced cell death
}

\author{
Cohausz, O ; Blenn, C ; Malanga, M ; Althaus, F R
}

\begin{abstract}
Poly(ADP-ribose) (PAR) has been identified as a DNA damage-inducible cell death signal upstream of apoptosis-inducing factor (AIF). PAR causes the translocation of AIF from mitochondria to the nucleus and triggers cell death. In living cells, PAR molecules are subject to dynamic changes pending on internal and external stress factors. Using RNA interference (RNAi), we determined the roles of poly(ADP-ribose) polymerases-1 and -2 (PARP-1, PARP-2) and poly(ADP-ribose) glycohydrolase (PARG), the key enzymes configuring PAR molecules, in cell death induced by an alkylating agent. We found that PARP-1, but not PARP-2 and PARG, contributed to alkylation-induced cell death. Likewise, AIF translocation was only affected by PARP-1. PARP-1 seems to play a major role configuring PAR as a death signal involving AIF translocation regardless of the death pathway involved.
\end{abstract}

DOI: https://doi.org/10.1007/s00018-008-7516-5

Posted at the Zurich Open Repository and Archive, University of Zurich

ZORA URL: https://doi.org/10.5167/uzh-3372

Journal Article

Published Version

Originally published at:

Cohausz, O; Blenn, C; Malanga, M; Althaus, F R (2008). The roles of poly(ADP-ribose)-metabolizing enzymes in alkylation-induced cell death. Cellular and Molecular Life Sciences, 65(4):644-655.

DOI: https://doi.org/10.1007/s00018-008-7516-5 


\title{
Research Article
}

\section{The roles of poly(ADP-ribose)-metabolizing enzymes in alkylation-induced cell death}

\author{
O. Cohausz ${ }^{\dagger}$, C. Blenn ${ }^{\dagger}$, M. Malanga ${ }^{+}$and F. R. Althaus* \\ Institute of Pharmacology and Toxicology, University of Zurich-Vetsuisse, Winterthurerstrasse 260, 8057 Zurich \\ (Switzerland), Fax: +41 446358 910, e-mail: fra@vetpharm.uzh.ch
}

Received 7 November 2007; received after revision 19 December 2007; accepted 21 December 2007 Online First 19 January 2008

\begin{abstract}
Poly(ADP-ribose) (PAR) has been identified as a DNA damage-inducible cell death signal upstream of apoptosis-inducing factor (AIF). PAR causes the translocation of AIF from mitochondria to the nucleus and triggers cell death. In living cells, PAR molecules are subject to dynamic changes pending on internal and external stress factors. Using RNA interference (RNAi), we determined the roles of poly(ADP-ribose) polymerases-1 and -2 (PARP-1,
\end{abstract}

PARP-2) and poly(ADP-ribose) glycohydrolase (PARG), the key enzymes configuring PAR molecules, in cell death induced by an alkylating agent. We found that PARP-1, but not PARP-2 and PARG, contributed to alkylation-induced cell death. Likewise, AIF translocation was only affected by PARP-1. PARP-1 seems to play a major role configuring PAR as a death signal involving AIF translocation regardless of the death pathway involved.

Keywords. Poly(ADP-ribose) (PAR), PARP-1, PARP-2, PARG, RNA interference, AIF, MNNG, caspase.

\section{Introduction}

Poly(ADP-ribose) polymerases-1 and -2 (PARP-1, PARP-2) and poly(ADP-ribose) glycohydrolase (PARG) are important components of the cellular DNA damage surveillance network $[1,2]$. PARP-1 and PARP-2 play a dual role as DNA damage sensors and signal transducers to downstream endpoints such as DNA repair and cell death pathways [3-7]. PARP-1 and PARP-2 bind rapidly to DNA strand breaks, become activated, and covalently modify themselves as well as other nuclear proteins. Large amounts of long and branched negatively charged poly (ADP-

\footnotetext{
These two authors contributed equally to this work.

Present address: Department of Functional and Structural Biology, University Federico II of Naples, Via Cinthia, Monte S. Angelo, 80126 Napoli (Italy).

* Corresponding author.
}

ribose) (PAR) molecules are synthesized at the expense of $\mathrm{NAD}^{+}$that is cleaved into ADP-ribose and nicotinamide. The constitutive intracellular levels of PAR are usually very low in unchallenged cells [8-10], but in response to DNA damaging agents, they increase 10-500-fold due to the activation of PARP-1 and PARP-2 [1, 2, 4, 11-13]. Poly(ADP-ribose) (PAR) accumulation is transient because PAR is rapidly degraded by PARG $[14,15]$. PARG differentially regulates PAR turnover by cleaving polymers both endoglycosidically and exoglycosidically, generating shorter polymers and free ADP-ribose, respectively [16]. In mammals, PARG is encoded by a single gene; however, it is expressed as multiple isoforms, which arise from alternative splicing $(99,102$ and $111 \mathrm{kDa}$, in human cells) [17]. PARG has a high specific activity and acts in concert with PARPs to maintain intracellular PAR levels at low concentrations under homeostatic conditions. The importance of this coor- 
dinated mechanism is underlined by the finding that failure to degrade PAR in PARG-knockout mice causes embryonic lethality [18].

Recently, Dawson and collaborators [19-21] demonstrated that PAR may act as a cell death signal upstream of apoptosis-inducing factor (AIF). AIF is a mitochondrial intermembrane flavoprotein that translocates to the nucleus in response to specific death signals [22]. In the nucleus, AIF triggers chromatin condensation as well as large-scale $(\sim 50 \mathrm{~kb})$ DNA fragmentation.

In the present study, we used RNA interference (RNAi) in human cells to selectively down-regulate PARP-1, PARP-2 and PARG, either separately or simultaneously, to determine their individual contributions to modulating PAR as a cell death signal. PARP activation was induced by the alkylating agent $N$-methyl- $N^{\prime}$-nitro- $N$ '-nitrosoguanidine (MNNG), that acts by formation of DNA adducts at nucleobases, resulting in induction of cell death through production of DNA strand breaks [23]. We used low concentrations $(50 \mu \mathrm{M})$ of MNNG to induce cell death, which produced substantial but not lethal damage to cells. Apart from silencing, we monitored the effects on cell death, PAR formation, AIF translocation and caspase activation. Our results suggest that of the two tested PARP enzymes, PARP-1 is the major contributor to the PAR signal inducing cell death and AIF translocation, but not caspase activation. Interestingly, RNAi-mediated silencing of PARG did not affect AIF translocation induced by MNNG, although it led to a significant accumulation of PAR.

\section{Materials and methods}

Cell culture. All media and supplements used for cell culturing were obtained from GIBCO (Invitrogen, Basel, Switzerland). Human cervical carcinoma cells (HeLa S3) and mouse embryonic fibroblasts (MEFs) were cultured at $37^{\circ} \mathrm{C}$ in a water-saturated $5 \% \mathrm{CO}_{2} /$ $95 \%$ air atmosphere, in Dulbecco's modified Eagle's medium (DMEM) containing $4500 \mathrm{mg} / \mathrm{l}$ glucose and supplemented with $10 \%(\mathrm{v} / \mathrm{v})$ fetal bovine serum (FBS) and antibiotics (complete DMEM).

Synthesis of small interfering RNAs and transfection. Small interfering RNAs (siRNAs) were synthesized in vitro from oligonucleotide templates (Microsynth, Balgach, Switzerland) using an siRNA construction kit (Ambion, Austin, TX, USA), according to manufacturer's instructions. Purified siRNAs were dissolved in water at a concentration of $20 \mu \mathrm{M}$ and stored at $-80^{\circ} \mathrm{C}$ until use. As targets for RNAi, 21-nucleotide sequences in the human coding region of PARP-1, PARP-2 and PARG cDNA were chosen following the instructions of the Ambion webpage based on the siRNA design guidelines first described by Tuschl and colleagues [24]. siRNA sequences shown in Fig. 1 (top) resulted in maximal silencing efficacies as compared to several tested siRNAs. A scrambled version of siRNA was also synthesized and used as a negative control.

Cells were grown to $50-70 \%$ confluence in 6-well plates and transfected with siRNAs at a final concentration of $80 \mathrm{nM}$ in $1000 \mu \mathrm{l}$ OptiMEM, using siPORT Amine (Ambion) as the transfection reagent. After incubation for $4 \mathrm{~h}$ at $37^{\circ} \mathrm{C}, 2 \mathrm{ml} /$ well complete DMEM was added and cells were allowed to grow for the times indicated. For time course experiments, cells were subcultured after $72 \mathrm{~h}$ and allowed to grow for indicated times. In cell growth experiments, silenced cells were harvested by trypsinization, seeded in sixwell plates and transfected again using exactly the conditions described above. In this way, several rounds of subculturing, transfection and growth were repeated on the same cell stocks. Cells were collected at various times after transfection to determine PARP-1 and PARP-2 protein and mRNA levels as well as PARG activity.

Cell extracts for PARG activity assay. Cells grown in 24-well plates were collected in $30 \mathrm{mM}$ Tris/ $\mathrm{HCl}$ ( $\mathrm{pH} 7.5$ ) buffer, containing $0.5 \mathrm{M} \mathrm{NaCl}, 20 \%(\mathrm{v} / \mathrm{v})$ glycerol and $1 \%$ Triton X-100 ( $0.5 \mathrm{ml} / \mathrm{well})$, and incubated for $30 \mathrm{~min}$ on ice. Whole-cell extracts were obtained after centrifugation at $10000 \mathrm{~g}$ for $10 \mathrm{~min}$ at $4^{\circ} \mathrm{C}$. Supernatants were divided into aliquots and stored at $-80^{\circ} \mathrm{C}$ until use.

Synthesis of PARP-bound $\left[{ }^{32}\right.$ P]PAR and PAR degradation assay. PARP-bound $\left[{ }^{32} \mathrm{P}\right] \mathrm{PAR}$ was synthesized in vitro, by incubation of 1.5 U PARP-1 (Biomol) in $100 \mathrm{mM}$ Tris/HCl ( $\mathrm{pH} 8.0)$ buffer, containing $400 \mu \mathrm{M}\left[{ }^{32} \mathrm{P}\right] \mathrm{NAD}^{+}(0.1 \mu \mathrm{Ci} / \mathrm{nmol}$, Perkin Elmer $)$, $10 \mathrm{mM} \mathrm{MgCl}_{2}, 2 \mathrm{mM}$ dithiothreitol (DTT), $0.5 \mu \mathrm{g}$ nicked calf thymus DNA, $10 \%(\mathrm{v} / \mathrm{v})$ ethanol and $10 \%$ glycerol, in a final volume of $27 \mu \mathrm{l}$. After $30 \mathrm{~min}$ of incubation at $30^{\circ} \mathrm{C}$, the reaction was stopped by precipitation with $0.7 \mathrm{vol}$. of propan-2-ol in the presence of $0.3 \mathrm{M}$ sodium acetate ( $\mathrm{pH}$ 5.2) [25]. The pellet containing PARP-bound $\left[{ }^{32} \mathrm{P}\right] \mathrm{PAR}$ was collected by centrifugation, washed with ethanol, air-dried and finally resuspended in $50 \mathrm{mM}$ Tris/ $\mathrm{HCl}(\mathrm{pH} 7.4)$, containing $14 \mathrm{mM}$ 2-mercaptoethanol, $0.5 \mathrm{mM}$ phenylmethylsulphonyl fluoride (PMSF) and $20 \%$ glycerol. This sample was subsequently used as a substrate to determine enzymatic PAR degradation in cell extracts. 


\begin{tabular}{|c|c|c|c|}
\hline $\begin{array}{c}\text { Target gene } \\
\text { (siRNA name) }\end{array}$ & $\begin{array}{c}\text { Accession } \\
\text { Number }^{1}\end{array}$ & $\begin{array}{c}\text { dsRNA } \\
\text { Region }\end{array}$ & Antisense sequence \\
\hline $\begin{array}{c}\text { PARP-1 } \\
\text { (siRNA-P1) }\end{array}$ & NM_001618 & 913-934 & 5'-AAGAGCGATGCCTATTACTGC-3' \\
\hline $\begin{array}{c}\text { PARP-2 } \\
\text { (siRNA-P2) }\end{array}$ & NM_005484 & $353-374$ & 5'-AAGATGATGCCAGAGGAACTC-3' \\
\hline $\begin{array}{c}\text { PARG } \\
\text { (siRNA-G) }\end{array}$ & NM_003631 & $\begin{array}{c}1865- \\
1886\end{array}$ & 5'-AAATGGGACTTTACAGCTTTG-3' \\
\hline
\end{tabular}

${ }^{1} \mathrm{NCBI}$ accession number for the sequences from which the dsRNAs were derived

A
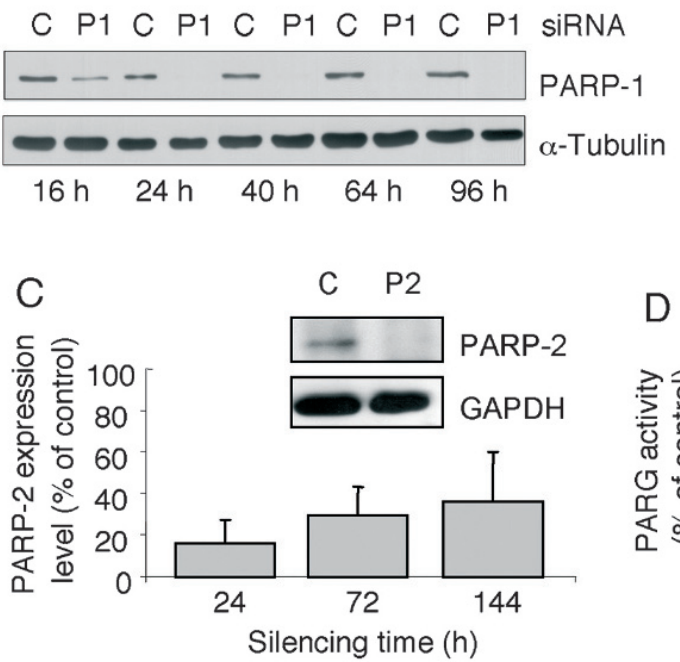

B

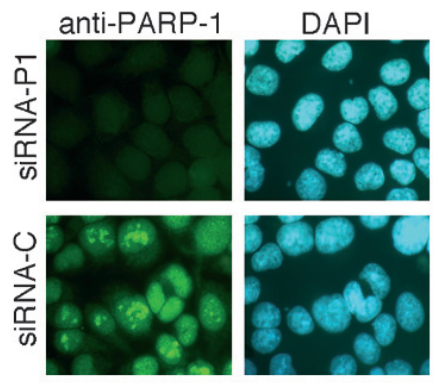

D

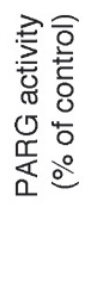

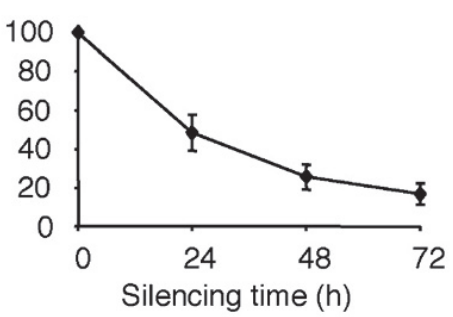

Figure 1. Specific knockdown of poly(ADP-ribose) polymerase (PARP)-1, PARP-2 and poly(ADP-ribose) glycohydrolase (PARG) by RNA interference (RNAi). The table shows selected genes for siRNA-mediated RNA interference. $(A)$ Western blot analysis of PARP-1 protein levels in HeLa cells transfected with control and PARP-1-specific siRNA at indicated time points after transfection. The amount of loaded protein was normalized to $\alpha$-tubulin. (B) PARP-1 detection by immunofluorescence of siRNA transfected HeLa cells after $24 \mathrm{~h}$. DAPI staining of cellular DNA is also shown. $(C)$ Relative fold-changes of PARP-2 expression after RNAi of PARP2 as detected by real time RTPCR at indicated time points and Western blot analysis $48 \mathrm{~h}$ after siRNA. Error bars indicate mean $\pm \mathrm{SD}$ in $\%$ of control of three independent experiments. $(D)$ PARG activity was analyzed as described in the Materials and methods section at different time points after transfection. All data were normalized to protein content and the values obtained with control cells were set at $100 \%$. Results represent means \pm SD for at least six independent experiments.
PARG activity was determined in cell extracts by an enzymatic assay using PARP-bound $\left[{ }^{32} \mathrm{P}\right] \mathrm{PAR}$ as a substrate and 2- $\mu$ l cell extracts as the enzyme source. Incubation was in $50 \mathrm{mM}$ potassium phosphate buffer (pH 7.4), containing $50 \mathrm{mM} \mathrm{KCl}, 10 \mathrm{mM}$ 2-mercaptoethanol and $100 \mu \mathrm{g} / \mathrm{ml} \mathrm{BSA} \mathrm{[25]} \mathrm{in} \mathrm{a} \mathrm{final} \mathrm{volume} \mathrm{of}$ $24 \mu \mathrm{l}$. Reactions were started by adding $200 \mathrm{pmol}$ protein-bound $\left[{ }^{32} \mathrm{P}\right] \mathrm{PAR}$ and allowed to proceed for $10 \mathrm{~min}$ at $37^{\circ} \mathrm{C}$. Then, an equal volume of ice-cold $40 \%$ (w/v) trichloroacetic acid was added and, after centrifugation at $13000 \mathrm{~g}$ for $15 \mathrm{~min}$, the radioactivity in the supernatant was measured in a liquid-scintillation counter (Beckmann). PARG activity in siRNAtransfected cells was expressed as percentage of the values detected for control cells, transfected with scrambled siRNA. Purified calf thymus PARG and $1 \mu \mathrm{M}$ ADP (hydroxymethyl) pyrrolidinediol (ADPHPD; Calbiochem, San Diego, CA, USA), a specific PARG inhibitor, were used as controls.

Western blot analyses. Cells were washed with icecold PBS and then harvested directly in Laemmli buffer (60 mM Tris- $\mathrm{HCl}, \mathrm{pH} 6.8,2 \%$ SDS, $2 \%$ 2- mercaptoethanol, $8 \%$ glycerol, $0.0025 \%$ bromphenol blue), sonicated and incubated for $1 \mathrm{~min}$ at $95^{\circ} \mathrm{C}$. Soluble proteins were collected in the supernatants after centrifugation, separated by electrophoresis on SDS-polyacrylamide gels and finally electroblotted on PVDF membranes (Bio-Rad, Hercules, CA, USA). Blots were probed with monoclonal anti-PARP-1 (Alexis, Lausen, Switzerland; C2-10; 1:5000), polyclonal anti-PARP-1 p85 fragment (Promega, Madison, WI, USA; 1:500), polyclonal anti-AIF (Serotec, Raleigh, NC, USA; 1:500), monoclonal anti-bax (Calbiochem; 1:2000), monoclonal anti-bcl-2 (Santa Cruz, c-2; 1:250), monoclonal anti-PARP-2 (Alexis; 4G8; 1:50), monoclonal anti-proliferating-cell nuclear antigen (PCNA; BD Biosciences, San Jose, CA, USA; 1:5000), monoclonal anti-p53 (Oncogene, ab-1; 1:5000), polyclonal anti-cleaved caspase-7 (Cell Signaling Technology, Boston, MA, USA; 1:1000), polyclonal anti-cleaved caspase-9 (Cell Signaling Technology; 1:1000), monoclonal anti-glyceraldehyde 3-phosphate dehydrogenase (GAPDH; Ambion, Austin, TX, USA; 1:80 000), monoclonal anti-manganese superoxide dismutase (MnSOD; BD Biosciences; 
1:1000), monoclonal anti-topoisomerase I (Topo-I, BD Biosciences; 1:5000) and monoclonal anti- $\alpha$ tubulin antibodies (Sigma, Buchs, Switzerland; 1:5000), in succession. Immunodetection was performed by ECL (Pierce, Rockford, IL, USA; ECL detection kit). Images were acquired by exposure to autoradiographic films.

PCR analyses. cDNA was produced from control and siRNA-transfected cells without prior isolation of RNA using the Cells-to-cDNA II kit (Ambion) under the conditions described in the manufacturer's manual. These samples were then used as templates for GAPDH, PARP-1 and PARP-2 amplification in quantitative real-time PCR, with specifically designed primers (Assay-on-demand Gene Expression products, Applied Biosystems, Foster City, CA, USA), in a reaction mixture including TaqMan Universal PCR Master Mix (Applied Biosystems). Real-time PCR analyses were carried out on an ABI PRISM 7700 cycler, at the default setting program $\left(95^{\circ} \mathrm{C}, 15 \mathrm{~s} ; 60^{\circ} \mathrm{C}\right.$, $1 \mathrm{~min} ; 40$ cycles). For the quantification of changes in gene expression, the $\Delta \Delta \mathrm{C}_{\mathrm{t}}$ method was used to calculate the relative fold changes normalized against GAPDH.

Immunofluorescence analyses. For PARP-1, at $24 \mathrm{~h}$ after transfection with either PARP-1-specific or scrambled siRNA, cells were subcultured and grown on cover slips for $24 \mathrm{~h}$. The medium was removed and cells were washed with ice-cold PBS and immediately fixed in $3 \%$ paraformaldehyde for $15 \mathrm{~min}$ at room temperature followed by incubation in $100 \mathrm{mM}$ glycine in PBS for $2 \mathrm{~min}$ at room temperature. After washing with PBS, cells were incubated with $3 \%$ milk, $0.05 \%$ Tween 20, in PBS (PBS-TM), for $1 \mathrm{~h}$ at $37^{\circ} \mathrm{C}$, and then exposed to a monoclonal antibody against PARP-1 (c2-10; Alexis) diluted 1:200 in PBS-TM for $1 \mathrm{~h}$ at $37^{\circ} \mathrm{C}$. For AIF/PAR, at $72 \mathrm{~h}$ after siRNA transfection, cells were subcultured and grown on cover slips for $24 \mathrm{~h}$. Treatment with $50 \mu \mathrm{M}$ MNNG was performed for $30 \mathrm{~min}$ in case of PAR, and for $6 \mathrm{~h}$ in case of AIF detection. After MNNG incubation, the drug containing medium was removed and cells were washed with ice-cold PBS and immediately fixed in methanol/acetone $(1: 1)$ for $20 \mathrm{~min}$ at $-20^{\circ} \mathrm{C}$. After washing with PBS, cells were incubated with $3 \%(w / v)$ milk in PBS (PBS-M) for $1 \mathrm{~h}$ at $37^{\circ} \mathrm{C}$ and then exposed to either a polyclonal antibody against PAR (LP9610; Alexis) diluted 1:200 in PBS-M or a polyclonal antibody against AIF (Serotec) diluted 1:200 in PBS$\mathrm{M}$ for $1 \mathrm{~h}$ at $37^{\circ} \mathrm{C}$. Finally, samples were incubated for $1 \mathrm{~h}$ at room temperature with an Alexa Fluor ${ }^{\circledR} 488$ conjugated secondary antibody (Molecular Probes, Invitrogen, Basel, Switzerland) diluted 1:200. DNA was stained either with 4', 6-diamidino-2-phenylindole (DAPI) or with Hoechst 33258 dissolved in PBS at $10 \mu \mathrm{g} / \mathrm{ml}$ or $0.2 \mu \mathrm{g} / \mathrm{ml}$, respectively. Cover slips were mounted on glass slides with $0.1 \%$ Mowiol (Calbiochem) and examined with a fluorescence microscope (Nikon) connected to a digital camera (Kappa, Gleichen, Germany).

Cell growth and viability assay. Cell growth and viability were assessed by a dye reduction bioassay (Alamar Blue assay; Serotec). Briefly, $72 \mathrm{~h}$ after transfection, confluent cells were harvested by trypsinization, resuspended in complete DMEM and seeded into 6-well (cell growth assay) or 96-well (cytotoxicity analyses) plates at a density of 250000 or 20000 cells/well, respectively. To determine druginduced cytotoxicity, MNNG was dissolved in DMSO at $2.0 \mathrm{M}$ and diluted in complete DMEM to final dilutions ranging from 10 to $500 \mu \mathrm{M}$ just before use. After attachment of cells to the bottom of the plates, complete DMEM containing MNNG was added to exponentially growing cells in 96-well plates. After 20 -h incubation at $37^{\circ} \mathrm{C}$, the medium was replaced with complete DMEM containing $10 \%$ (v/ v) Alamar blue. Metabolic reduction of the vital dye was assessed by spectrofluorimetry: fluorescence was monitored at $530 \mathrm{~nm}$ excitation wavelength and $590 \mathrm{~nm}$ emission wavelength, using an LS 55 luminescence spectrometer (Perkin-Elmer, Wellesley, MA, USA). In cytotoxicity experiments, the broad spectrum caspase inhibitors benzyloxycarbonyl-Val-AlaAsp-(O-Me)fluoromethyl ketone (Z-VAD.fmk; $100 \mu \mathrm{M}$; Calbiochem) and Gln-Val-Asp(non-O-methylated)-OPh (Q-VD-OPh; $20 \mu \mathrm{M}$; Calbiochem) were added to the culture medium as indicated for the entire treatment time. Twelve-fold determinations of each sample were performed on a single experiment. Based on the results shown in Figure S2, $50 \mu \mathrm{M}$ concentrations of MNNG were used in all subsequent experiments.

Measurement of the ADP/ATP ratio. The ADP/ ATP ratio was determined using the ApoGlow kit (LumiTech Ltd., Nottingham, UK); the assay is based on bioluminescence measurement of the adenylate nucleotides and allows the assessment of the mode of cell death [26]. Cells were grown in white clear-bottom 96-well plates and treated exactly as indicated above; at different times after treatment, cells were lysed in nucleotide-releasing reagent and processed for ATP and ADP determination as described in the kit's instruction manual. Luminescence was measured using the MLX microtiter plate luminometer (Dynex Technologies, Chantilly, VA, USA). Quintuplicate determinations 
of each sample were performed on a single silencing experiment.

PAR analysis. Cells were transfected with the indicated siRNAs and treated with $50 \mu \mathrm{M}$ MNNG for $1 \mathrm{~h}$. For control experiments, cells were grown in the presence of the PARP-inhibitor 3-aminobenzamide (3-AB, $3 \mathrm{mM}$ ) for $1 \mathrm{~h}$ before and during the entire subsequent treatment time. Then, adherent cells were washed in situ with PBS, overlaid with $100 \mathrm{mM}$ Tris/ $\mathrm{HCl}$ (pH 8.0) containing $10 \mathrm{mM} \mathrm{MgCl}, 2 \mathrm{mM}$ DTT, $20 \mu \mathrm{g} / \mathrm{ml}$ digitonin and $1 \mu \mathrm{Ci}\left[{ }^{32} \mathrm{P}\right] \mathrm{NAD}^{+}$and incubated for $15 \mathrm{~min}$ at $37^{\circ} \mathrm{C}$. At the end of the incubation time, citric acid was added to a final concentration of $25 \mathrm{mM}$; cells were harvested, transferred on to ice and immediately precipitated by addition of trichloroacetic acid ( $20 \%$, final concentration). Trichloroacetic acid pellets were collected by centrifugation, washed three times with ethanol and once with diethyl ether. At this step, incorporation of $\left[{ }^{32} \mathrm{P}\right] \mathrm{NAD}^{+}$was assessed by measuring the radioactivity in a liquid-scintillation counter (Beckmann). Finally, the pellet was resuspended in TE buffer $(10 \mathrm{mM}$ Tris/ $\mathrm{HCl}, \mathrm{pH} 8.0$, and $1 \mathrm{mM}$ EDTA) containing $0.5 \mathrm{mg} / \mathrm{ml}$ proteinase $\mathrm{K}$ (Sigma). After overnight incubation at $37^{\circ} \mathrm{C}$, the $\mathrm{pH}$ was raised to 12.0 by Tris $/ \mathrm{NaOH}$ addition; samples were further incubated for $1 \mathrm{~h}$ at $60^{\circ} \mathrm{C}$ and finally subjected to high-resolution PAGE and autoradiography. Polymer size distributions were analyzed by densitometric scanning and quantification of autoradiographic band intensities (ImageQuant 3.15; Molecular Dynamics/GE Healthcare).

Annexin V staining. Either untreated or MNNGtreated cells were double-stained for annexin $\mathrm{V}$ and propidium iodide (PI) using the Annexin-V-Fluos Staining Kit (Roche, Basel, Switzerland) according to the manufacturer's protocol. Briefly, following $8 \mathrm{~h}$ and $24 \mathrm{~h}$ of drug treatment $(50 \mu \mathrm{M}$ MNNG), total cells grown in 6-well plates were washed with PBS and typsinized. Subsequently, annexin V-fluorescein and PI were added to the cells, which were incubated for $15 \mathrm{~min}$ at room temperature in the dark. After incubation, cells were washed once with PBS, resuspended and examined by fluorescence microscopy analysis. From each sample, 1200 cells $(8 \mathrm{~h})$ and 1900 cells $(24 \mathrm{~h})$ were analyzed for annexin $\mathrm{V}$ and PI staining in two independent experiments. Total cell numbers were determined by cell counting using a Neubauer counting chamber.

Cellular subfractionation. Cellular subfractionation was performed as described [27]. Briefly, HeLa cells were harvested and washed twice with $1 \mathrm{mM}$ Tris$\mathrm{HCl}(\mathrm{pH} 7.0), 0.13 \mathrm{M} \mathrm{NaCl}, 5 \mathrm{mM} \mathrm{KCl}, 7.5 \mathrm{mM}$
$\mathrm{MgCl}_{2}$. After incubation in $3.5 \mathrm{mM}$ Tris- $\mathrm{HCl}$ ( $\mathrm{pH} 7.8$ ), $3 \mathrm{mM} \mathrm{NaCl}, 0.5 \mathrm{mM} \mathrm{MgCl}_{2}$ for $5 \mathrm{~min}$, cells were mechanically broken. The homogenate was immediately mixed with one-ninth of the cell volume of $0.35 \mathrm{M}$ Tris- $\mathrm{HCl}(\mathrm{pH} 7.8), 0.2 \mathrm{M} \mathrm{NaCl}$, $50 \mathrm{mM} \mathrm{MgCl}_{2}$, and spun for $3 \mathrm{~min}$ at $1600 \mathrm{~g}$ to pellet unbroken cells, debris and nuclei. The pellet was harvested directly in Laemmli buffer and the supernatant was recentrifuged under the same conditions. The final supernatant was spun at $13000 \mathrm{~g}$ for $1 \mathrm{~min}$ and the resulting mitochondrial pellet was washed once with $35 \mathrm{mM}$ Tris- $\mathrm{HCl}$ (pH 7.8), $20 \mathrm{mM} \mathrm{NaCl}$, $5 \mathrm{mM} \mathrm{MgCl}$, then twice with $10 \mathrm{mM}$ Tris- $\mathrm{HCl}$ (pH 7.4), $1 \mathrm{mM}$ EDTA, $0.32 \mathrm{M}$ sucrose and finally resuspended in Laemmli buffer. The entire purification process was performed at $4^{\circ} \mathrm{C}$ and a protease inhibitor cocktail (Complete ${ }^{\mathrm{TM}}$, EDTA-free; Boehringer, Ingelheim, Germany) was added to all Tris buffers at the recommended concentration just before use. Whole mitochondria fraction and onetenth of the nuclear fraction were used for SDSPAGE and Western blot analysis. For quantification, band intensities were measured by scanning densitometry using the ImageQuant software (Molecular Dynamics/GE Healthcare) and data were normalized to mitochondrial (MnSOD) and nuclear (TopoI) markers, respectively.

Other methods. Protein concentration was determined either by the method of Lowry et al. [28] or using the Bradford protein assay reagent (Bio-Rad), with BSA as a standard.

Supplemental material. All supplemental information (Figures S1-S4) are available on our website www.vetpharm.uzh.ch/suppl/.

\section{Results}

Knocking-down PARP-1, PARP-2 and PARG gene expression by RNAi. We used RNAi to selectively down-regulate PARP-1, PARP-2 and PARG expression in the human cancer cell line HeLa. From the coding region of human PARP-1, PARP-2 and PARG cDNA, 21-nucleotide sequences were selected as targets for RNAi and the corresponding siRNAs (Fig. 1, top, describing the names of the selected genes, their NCBI accession numbers and the regions from which dsRNAs were derived) were synthesized in vitro as described under Materials and methods. A scrambled version of these siRNAs was used as negative control (siRNA-C). To examine the effect of siRNAs on the expression of PARP-1, a timecourse analysis of PARP-1 protein expression was 
carried out in whole cell lysates. As shown in Fig. 1A, transfection of HeLa cells with PARP-1-specific siRNA reduced PARP-1 protein expression by $16 \mathrm{~h}$, and remained at low/undetectable levels from 24 to $96 \mathrm{~h}$. Figure 1B shows the effect of PARP-1 silencing by indirect immunofluorescence. The green nuclear signal, identified with monoclonal anti-PARP-1 antibody, was abolished by $24 \mathrm{~h}$ [Fig. 1B (siRNA-P1)], while it remained unchanged in cells transfected with control siRNA (siRNA-C). When we established transient knockdown of PARP-2 gene expression, quantification by real-time RT-PCR confirmed a maximal decrease in PARP-2 mRNA levels that reached values of $16.1 \%$ at $24 \mathrm{~h}$ after transfection with siRNA-P2 and a time-dependent recovery to $29.7 \% \quad(72 \mathrm{~h})$ and $36.2 \% \quad(144 \mathrm{~h})$, respectively (Fig. 1C). PARP-2 protein levels were decreased to $15.6 \% 48 \mathrm{~h}$ after RNAi specific for PARP-2 (Fig. 1C). To determine the silencing efficacy of PARG siRNA (siRNA-G) on PAR catabolism, PARG activity was quantified in transfected cells. A time-course experiment of PAR-degrading activity was carried out in whole-cell lysates. After transfection into HeLa cells, siRNA-G caused a progressive loss of enzymatic activity that was maximal after $72 \mathrm{~h}(84 \pm 7 \%)$ (Fig. 1D).

Generally, the average silencing efficacy of our experiments was $90 \pm 10 \%$ for PARP- $1,70 \pm 13.5 \%$ for PARP-2 and $84 \pm 7 \%$ for PARG, $72 \mathrm{~h}$ after specific siRNA. In all experiments, a scrambled siRNA was completely ineffective, as judged by comparison with non-transfected cells, and hence was taken as the negative control. In addition, no apoptotic fragmentation of PARP-1 [29] was detected in RNAi experiments, confirming the absence of primary (transfection-related) or secondary (PARP/PARG downregulation-related) cytotoxic effects (see below). Furthermore, PARP as well as PARG silencing did not cause any morphological changes, growth defects or cell death, as assessed by light microscopy, cell counting, viability assays and biochemical analyses of protein expression (Fig. S1 and data not shown). Silenced cells retained the ability to attach and proliferate under routine subculture conditions and even recurrent transfections on successive subcultures did not affect the cell growth of silenced HeLa cells (Fig. S1).

Effect of PARP-1, PARP-2 and PARG silencing on PAR metabolism. We next examined the effects of PARP-1, PARP-2 and PARG down-regulation on PAR synthesis in DNA-damaged cells by immunofluorescence analysis. In the experiment illustrated in Figure 2A, HeLa cells were subcultured $72 \mathrm{~h}$ after transfection with siRNA and grown on cover slips for
$24 \mathrm{~h}$ before exposure to the alkylating agent MNNG $(50 \mu \mathrm{M})$ for $30 \mathrm{~min}$. As expected, MNNG-induced polymer synthesis was suppressed by PARP-1 silencing and by pharmacological inhibition of PARP activity (3-AB). PARP-2 silencing had no visible effect on PAR formation, whereas simultaneous down-regulation of PARP-1 and PARP-2 abrogated MNNG-induced PAR formation. However, large amounts of PAR were formed in PARG-siRNAtransfected cells that clearly exceeded the PAR formation levels of control cells. Triple silencing (siRNA-P1, -P2, -G) led to PAR formation comparable to levels seen in control cells.

Given the inherent limitations of immunofluorescence microscopy, it is difficult to monitor small changes in PAR formation. Therefore, we directly analyzed the PAR molecules synthesized under various silencing conditions.

ADP-ribose incorporation was low in untreated control as well as in PARP-1-, PARP-2- and PARG-downregulated cells, but markedly stimulated after moderate doses of MNNG (Fig. 2B). As expected, this increase was reduced in PARP-1, and to a lesser extent, in PARP - 2-down-regulated cells. Simultaneous down-regulation of PARP-1 and PARP-2, as well as pretreatment with the PARP-inhibitor 3-AB, abrogated MNNG-induced PAR formation. In contrast, PARG silencing led to an increase in PAR. Triple silencing (siRNA-P1, -P2 and -G) led to PAR formation comparable to control cells, as both PAR synthesis and PAR degradation were suppressed within these cells.

We next focused on the size of PAR molecules synthesized under various silencing conditions using SDS-PAGE (Fig. 2C, D). Under basal conditions, control as well as PARP-1-, PARP-2- and PARG-down-regulated cells showed generally low levels of intracellular PAR. PAR levels of PARP-1and PARP-2-down-regulated cells exhibited no differences in comparison to control cells, apart from a marginal decrease in polymers of short and medium length ( $<20$ ADP-ribose units). In contrast, a slight increase in short and medium $(<20$ ADP-ribose units) and particularly long ( $>20$ ADPribose units) polymers could be observed in PARGsilenced cells (Fig. 2C, D). As expected, MNNGinduced PAR formation of control cells was reduced in PARP-1-silenced, and to a lesser extent, in PARP-2-silenced cells. By contrast, an accumulation of PAR was observed in PARG-siRNA-transfected cells, reflecting a reduced degradation of polymers. Furthermore, the quantification of individual PAR molecules showed an increase in polymers of short, medium and long sizes after MNNG treatment in PARG-silenced cells 
A
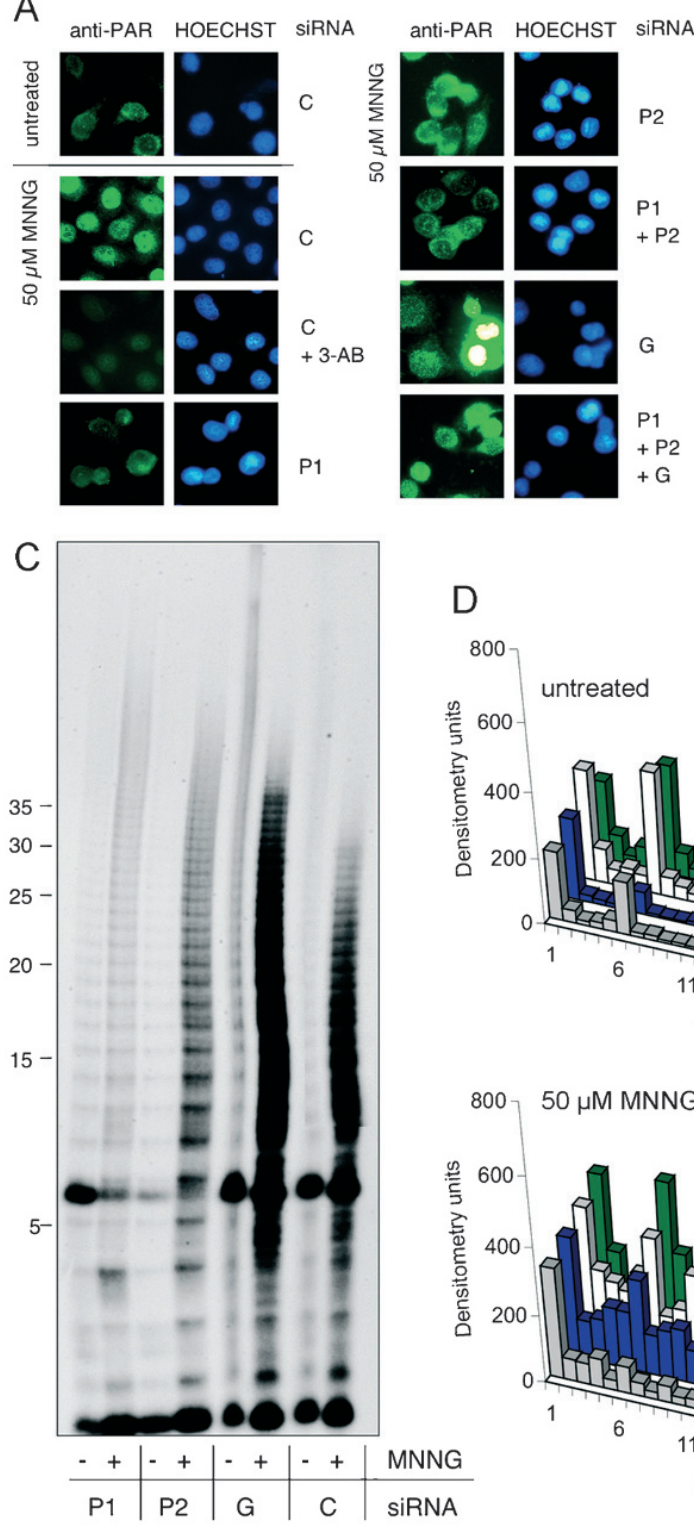

B
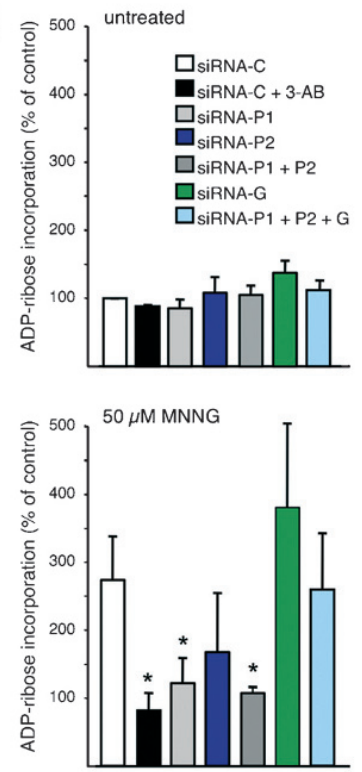

D

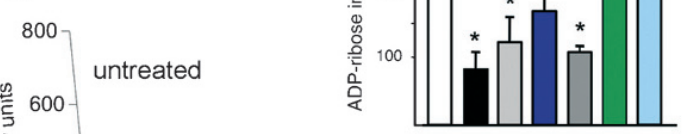

(Fig. 2D). Taken together, RNAi allows us to selectively down-regulate the major contributors to PAR metabolism and thus modulate the PAR signal leading to cell death [19-21].

Monitoring alkylation-induced cell death: Effect of PARPs and PARG silencing. Using fluorescence microscopy, we analyzed cell numbers, and annexin $\mathrm{V}$ and PI staining (Fig. 3A). Cell death induced by $50 \mu \mathrm{M}$ MNNG progresses from $55 \%$ at $8 \mathrm{~h}$ to $80 \%$ at $24 \mathrm{~h}$. At $8 \mathrm{~h}$, a marked proportion of cells $(13 \%)$ became annexin $\mathrm{V}$ positive, indicating apoptotic cell death. Half of these annexin V-positive cells appeared to be PI positive at the same time, whereas only a low proportion of cells was stained exclusively for PI. At

Figure 2. Analyses of poly(ADP-ribose) (PAR) synthesis in HeLa cells after RNAi against PARP-1, PARP-2 and PARG. (A) Immunofluorescence analysis of PAR levels in HeLa cells transfected with siRNA or treated with 3-aminobenzamide (3AB) as indicated immediately after treatment with $50 \mu \mathrm{M} \mathrm{N}$ methyl- $N$ '-nitro- $N$-nitrosoguanidine (MNNG) for 30 min. (B) De novo synthesis of PAR after $1 \mathrm{~h}$ of $50 \mu \mathrm{M}$ MNNG treatment in HeLa cells. Stressed cells were made permeable by a mild digitonin shock to allow the uptake of radiolabeled $\mathrm{NAD}^{+}$as described in Materials and methods. The average radioactivity incorporation of three independent experiments is shown $(* p<0.05$, unpaired $t$-test). The values are normalized to untreated control cells. HeLa cells were transfected with small interfering RNA (siRNA) or treated with 3-AB as indicated. (C) PAR analysis by PAGE and autoradiography detection after 1-h treatment with $50 \mu \mathrm{M}$ MNNG as described in Materials and methods section. $(D)$ Quantification of $(C)$ was carried out by scanning densitometry of individual bands with ImageQuant software (Molecular Dynamics/GE Healthcare). the later time-point $(24 \mathrm{~h})$, the proportion of annexin $\mathrm{V}$-positive cells that was PI positive at the same time increased, whereas fewer cells appeared to be exclusively annexin $\mathrm{V}$ positive. Again, only a low proportion of cells was stained exclusively for PI. Taken together, our data indicate at both time points that the majority of cells die by apoptosis (annexin $\mathrm{V}$ positive), whereas only a negligible number of cells undergo necrosis (exclusively PI positive).

Figure 3B shows the effects of PARP-1, PARP-2 and PARG silencing on the cytotoxicity of $50 \mu \mathrm{M}$ MNNG. PARP-1 silencing increased HeLa cell survival from $13 \pm 4.3 \%$ to $27 \pm 5.6 \%$, while PARP-2 and PARG silencing had no significant effect. Similar findings were obtained in mouse embryonic fibroblasts show- 
A

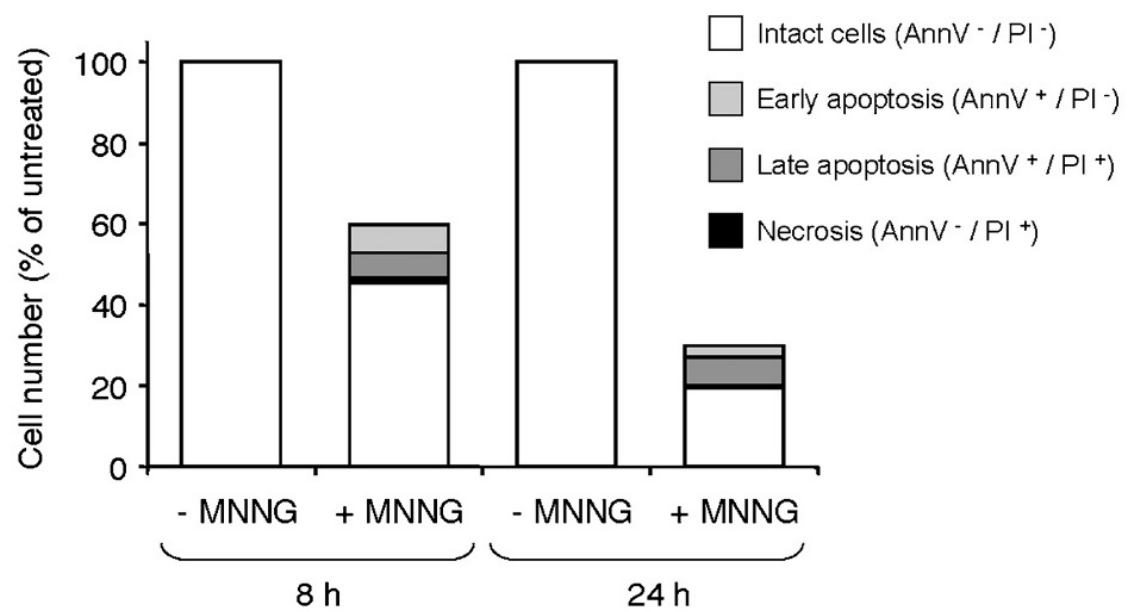

B

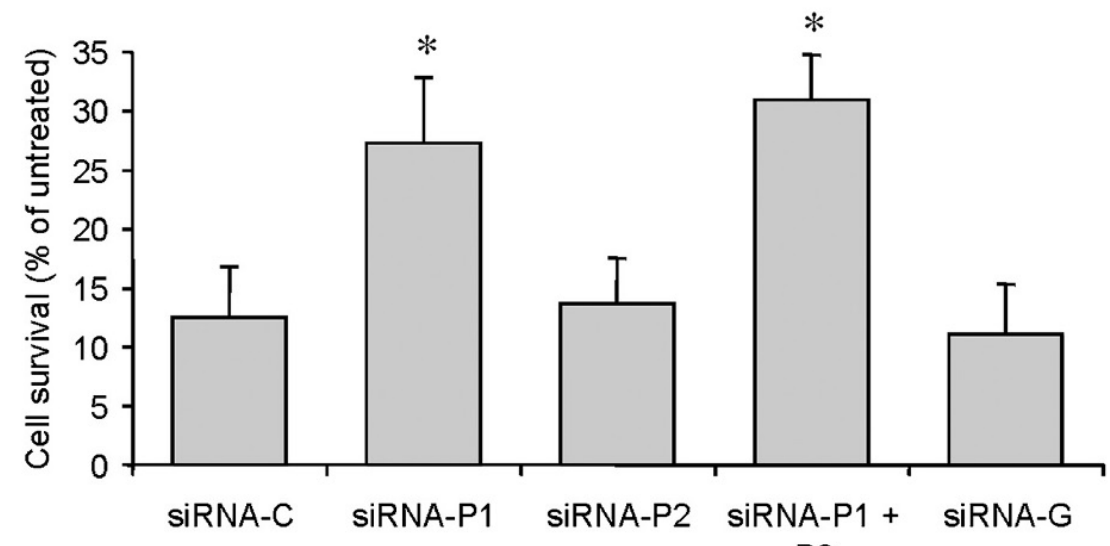

P2

C

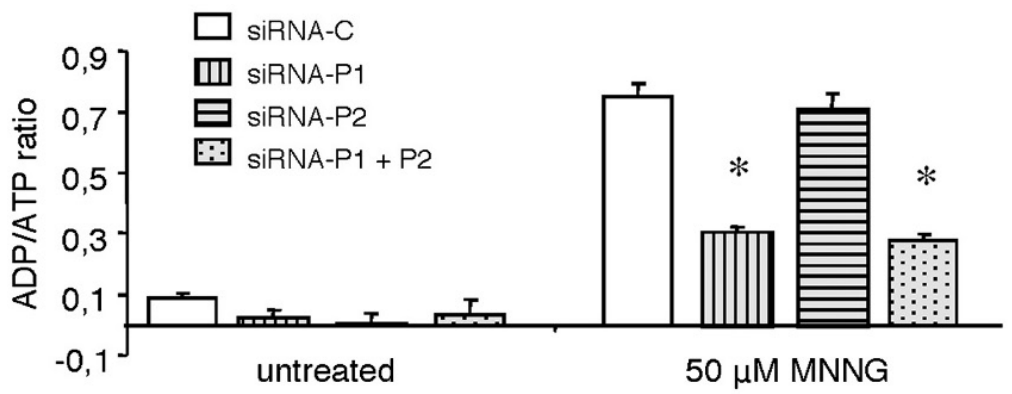

Figure 3. MNNG-induced death in HeLa cells. (A) HeLa cells were treated with $50 \mu \mathrm{M}$ MNNG for indicated time points. Positive staining for annexin $\mathrm{V}$ and propidium iodide (PI) was assessed by fluorescence microscopy analysis and expressed as percent of the untreated control cells. Results represent the means of two independent experiments. Total cell numbers were determined by cell counting using a Neubauer counting chamber. $(B) \mathrm{Ex}^{-}$ ponentially growing $\mathrm{HeLa}$ cells transfected with siRNAs for $72 \mathrm{~h}$ as indicated were treated with $50 \mu \mathrm{M} \mathrm{MNNG}$ for $24 \mathrm{~h}$. Cell viabilities were detected by the Alamar blue assay and expressed as a percent of the untreated control cells. Results represent the means \pm SD for at least three independent experiments $(*$ $p<0.005$, unpaired $t$-test). (C) ADP/ATP ratio measurement. HeLa cells were treated with MNNG $(50 \mu \mathrm{M})$ and processed for luminescence detection of the adenylate nucleotides after $8 \mathrm{~h}$. Results are the means \pm SD for quadruplicate determinations $(*$ $p<0.0001$, unpaired $t$-test). ing that PARP-1 silencing protected against MNNGinduced cell death, whereas PARG silencing did not [30]. Simultaneous down-regulation of PARP-1 and PARP-2 offered no additional cytoprotection in HeLa cells as compared to PARP-1-silenced cells. Taken together, our data demonstrate an alkylation-induced cell death in HeLa cells that can be prevented in part by PARP-1 silencing.

One of the early hallmarks of cell death is a moderate increase in the ADP/ATP ratios from 0.1 to 1.0 for apoptotic cells and a dramatic increase beyond 1.0 in cells undergoing necrosis $[26,31]$. The ADP/ATP ratios shown in Figure 3C confirmed the 'healthy status' of untreated HeLa cells, with a value below 0.1. Silencing of PARP-1, PARP-2 or PARP-1 + PARP-2 did not raise the ratio above 0.1 . However, after treatment with $50 \mu \mathrm{M}$ MNNG, the ADP/ATP ratio increased to a maximum of $0.75 \pm 0.04$ in control cells, indicative of apoptotic cell death. PARP-1 silencing had a cytoprotective effect, while PARP-2 silencing was ineffective. Likewise, double silencing of PARP-1 and PARP-2 was cytoprotective to MNNG-treated HeLa cells, but no more than single silencing of PARP-1.

Involvement of caspases in MNNG-induced cell death. The role of caspase activation in MNNG- 
induced cell death was monitored using the broadspectrum caspase inhibitors Z-VAD.fmk and Q-VD$\mathrm{OPh}$, and by measuring the formation of the typical cleavage products of PARP-1 and caspases-7 and -9. MNNG-induced cell death was prevented to $90 \%$ by either of the pan-caspase-inhibitors Z-VAD.fmk and Q-VD-OPh (Fig. 4A), suggesting a strong involvement of caspases. This was also evident with the appearance of the PARP-1 cleavage product and caspases-7 and -9 cleavage fragments (Fig. 4C). None of the silencing treatments affected the formation of cleavage products, suggesting that this process is not dependent on PARPs or PARG. Nevertheless, activation of caspases-7 and -9 could be completely blocked with the caspase-inhibitor Q-VD-OPh (Fig. 4B).

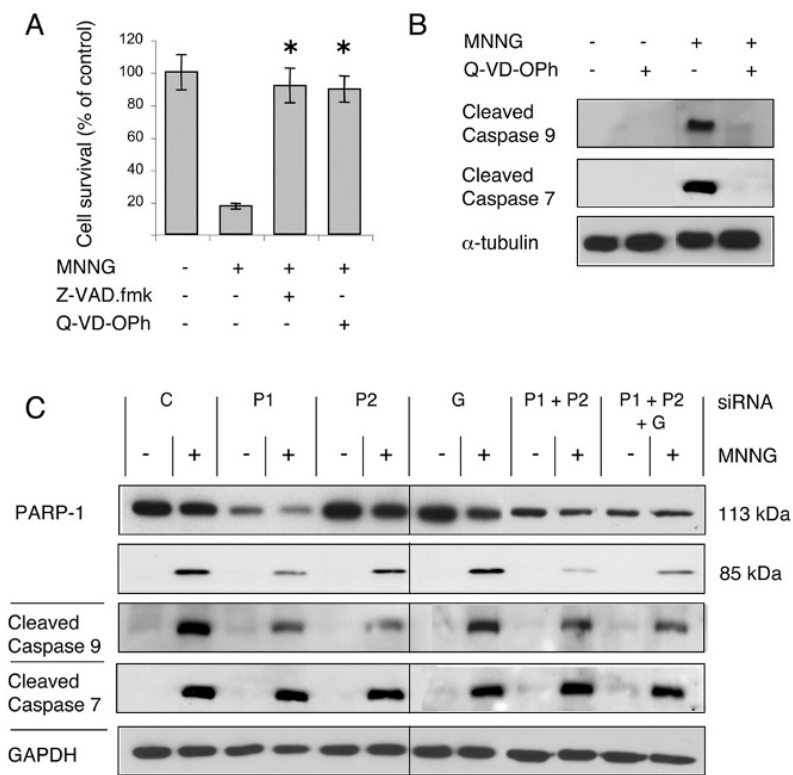

Figure 4. Low doses of the DNA alkylating agent MNNG induced caspase-dependent apoptotic cell death. $(A)$ Exponentially growing HeLa cells were treated with MNNG $(50 \mu \mathrm{M})$ in absence or presence of the broad-spectrum caspase-inhibitors Z-VAD.fmk $(100 \mu \mathrm{M})$ and Q-VD-OPh $(20 \mu \mathrm{M})$. After $20 \mathrm{~h}$ cells were analyzed by Alamar Blue assay to determine the cell viability as described in Materials and methods. Cell viabilities were expressed as percent of untreated control cells. Results represent the means \pm SD for at least six determinations ( $* p<0.0001$, unpaired $t$-test). (B) Western blot analysis of cleaved caspase-7 and -9 in the absence or presence of the caspase-inhibitor Q-VD-OPh. HeLa cells were treated for $20 \mathrm{~h}$ with MNNG $(50 \mu \mathrm{M})$ in absence or presence of the broadspectrum caspase-inhibitor Q-VD-OPh $(20 \mu \mathrm{M})$. Immunoblotting of whole cell lysates was performed with antibodies detecting activated caspase-7 and -9. (C) Western blot analysis of caspasedependent cleavage of PARP-1 as well as activated caspase-7 and caspase- 9 after MNNG-induced cell death. Cells transfected with siRNA were treated with $50 \mu \mathrm{M}$ MNNG for $20 \mathrm{~h}$ as indicated. Immunoblotting of whole cell lysates was performed with antibodies detecting the full-length form and the $85-\mathrm{kDa}$ fragment of PARP-1 as well as cleaved caspase-7 and caspase-9. The blots were exposed longer than those of Fig. 1A to visualize potentially low amounts of cleavage fragments.
Taken together, the pan-caspase-inhibitors, ZVAD.fmk and Q-VD-OPh, were able to almost completely block MNNG-induced toxicity, and Western blot analysis revealed a PARP-1-cleavage product as well as caspase-7 and caspase-9 activation. These data together with the results of the ADP/ATP assay indicate that low doses of the alkylating agent MNNG induced a caspase-dependent apoptotic cell death.

The role of PARP-1, PARP-2 and PARG in MNNGinduced AIF translocation. Cell death triggered by PAR may be mediated by AIF $[19,20]$, a mitochondrial flavoprotein that translocates to the nucleus. We determined which of the PAR-metabolizing enzymes contribute to the synthesis of PAR triggering AIF translocation. PARP-1, PARP-2 and PARG were silenced either singly or in combination and $\mathrm{HeLa}$ cells were challenged with $50 \mu \mathrm{M}$ MNNG. AIF translocation was monitored by immunofluorescence (Fig. 5A). MNNG treatment caused AIF translocation into the nucleus in $57 \%$ of cells (Fig. 5A), and this was reduced to $33 \%$ in PARP-1-silenced cells (Fig. 5A). In addition, we isolated mitochondria and nuclei and determined AIF distribution in these two fractions by Western blot analysis (Fig. 5B), using manganese superoxide dismutase (MnSOD) and topoisomerase I as mitochondrial and nuclear marker proteins, respectively. Neither of the PARPs nor PARG silencing per se had an effect on the localization of AIF. However, PARP-1 silencing strongly inhibited AIF translocation from mitochondria to the nucleus following MNNG-treatment of HeLa cells. Similar findings were observed in cells where PARP-1 and PARP-2 were simultaneously down-regulated, whereas PARP-2 or PARG silencing did not effect the translocation of AIF (Fig. 5B). To assess possible cross contamination, mitochondrial and nuclear fractions of three independent experiments were analyzed by immunoblot analyses concurrently with antibodies specific for MnSOD and Topo-I (Fig. S4). Generally, the amounts of cross contamination within the fractionation experiments differed slightly, explaining the rather strong signal of AIF in the nuclei of control and PARG-down-regulated cells in the absence of MNNG in comparison to the signal of AIF in the nuclei of untreated control as well as PARP-1-, PARP-2- and PARP-1/PARP-2-silenced cells (Fig. 5B). Quantification of Western-blot analysis confirmed AIF translocation after MNNG treatment in control as well as PARP-2- and PARG-down-regulated cells, whereas AIF translocation was inhibited after PARP-1-downregulation and the double silencing of PARP-1 and PARP-2. 
A

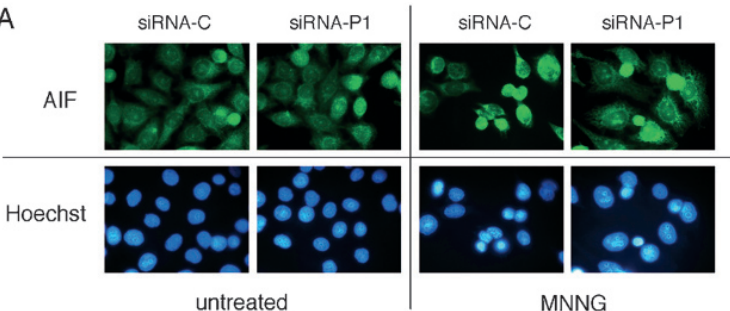

B
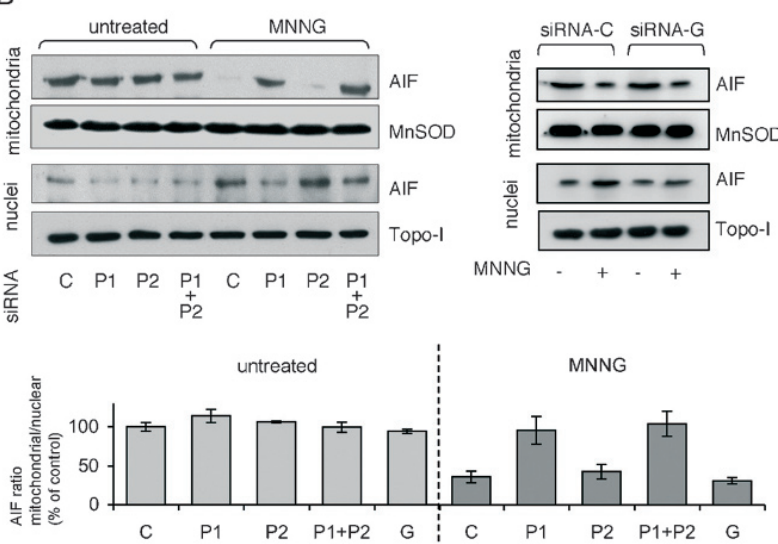

Figure 5. Influence of PARP-1, PARP-2 and PARG knockdown on the translocation of apoptosis-inducing factor (AIF) after MNNG- induced cell death. (A) Immunofluorescence analysis of AIF in HeLa cells transfected with control or PARP-1-specific siRNA after $6 \mathrm{~h}$ of MNNG treatment. (B) Analysis of AIF translocation by subcellular fractions. SiRNA-transfected cells (as indicated) treated with $\mathrm{MNNG}(50 \mu \mathrm{M})$ were subjected to subcellular fractionation and immunoblotting as described in Material and methods. (C) Analysis of the mitochondrial to nuclear AIF ratio as described under Materials and methods. The ratios indicate the value of mitochondrial AIF over nuclear AIF relative to siRNA-C transfected untreated control cells.

\section{Discussion}

In an elegant series of studies, Dawson and collaborators $[20,21]$ elucidated PAR as a cell death signal. In particular, PAR was found to mediate between DNA damage and the translocation of AIF from mitochondria to the nucleus. Another study focusing on MNNG-induced cell death and AIF release, suggested sequential activation of PARP-1, calpains, Bax and AIF in a single cell death pathway [32]. All of these studies were performed with high doses of MNNG $(500 \mu \mathrm{M})$ inducing a caspase-independent necrotic form of programmed cell death.

In the present study, we chose a low dose $(50 \mu \mathrm{M})$ MNNG treatment that triggers apoptotic cell death. This type of cell death involves moderate activation of PAR synthesis, moderate changes in the ADP/ATP ratio of cells, activation of caspases-7 and -9 , proteolytic processing of PARP-1, and AIF translocation from mitochondria to the nucleus. No changes were observed in the expression of Topo-I, p53, PCNA, bcl2, and bax (Fig. S3).
Dissecting the contribution of several PAR-metabolizing enzymes by RNAi in living cells, we observed that only PARP-1, and not PARP-2 and PARG, are involved in this type of cell death. Surprisingly, PARG-silencing did not affect the translocation of AIF and consequently had no impact on the cell death response of these cells, although it caused quite drastic changes in the pattern of PARs synthesized. Naturally, the absence of a PARG- and PARP-2-silencing effect may be attributable to residual molecules. In the case of PARG, there are about 50000 molecules in mammalian cells $[14,33]$, and following the $90 \%$ silencing achieved with the present protocol, about 5000 PARG molecules would escape down-regulation. In addition ADP-ribose-(arginine) protein hydrolase 3 (AHR3) catalyzes an alternative enzymatic activity for the degradation of poly(ADP-ribose) and must therefore be taken into account for residual PAR degradation activity within PARG-silenced cells [34]. However, at this level, we see a dramatic accumulation of PAR molecules (Fig. 2, [30]), suggesting that silencing is sufficient to visibly reduce PAR catabolism, and this is sufficient to provide a substantial protection of both human and murine cells against oxidant-induced apoptosis ([30], unpublished data). Thus, it seems that the type of PAR molecules relevant for MNNG-induced cell death is primarily determined by PARP-1. Likewise, PARP-1 seems to participate in the events affecting the ADP/ATP ratio and AIF translocation from mitochondria to nuclei, but not in the activation of caspases-7 or -9 .

In contrast to recently published data showing that MNNG-mediated necrosis proceeds in a caspaseindependent manner [32], we observed that PAR polymer-induced cell death in HeLa cells after low doses of MNNG treatment could be prevented by caspase inhibition. In addition, we observed caspase cleavage of PARP-1 as well as caspases-7 and -9 activation, in combination with the results of the ADP/ATP-ratio assay, further corroborating an apoptotic form of cell death after low doses of MNNG.

Our results confirm the concept of an intrinsic cell death pathway triggered by PAR [21, 35]. The polymer pattern obtained with low doses of MNNG (up to 35 ADP-ribose units) was capable of triggering AIF release and apoptosis. This finding was in agreement with recent studies showing that an $80 \mathrm{nM}$ of 16unit polymers already cause a moderate AIF release, whereas $80 \mathrm{nM}$ of 30 -unit polymers induces significant and $80 \mathrm{nM}$ of more than 60-unit polymers (or mixed polymers) a robust AIF release [20]. How the polymer branching impacts on these parameters is not known at present. However, in general, branching increases with PAR size [36, 37]. We identified PARP-1 as the major configurator of PAR as a cell death signal, while 
PARP-2 and PARG had no measurable influence under the silencing conditions shown. In agreement with recent reports $[19,20,32]$, PAR induces AIF release, which then translocates from mitochondria to the nucleus, leading to nuclear condensation and programmed cell death. Moreover, whether highdose-MNNG-mediated necrotic cell death is induced $[20,32]$ or whether apoptotic cell death by low doses of the alkylating agent was analyzed, this did not change the death link between PARP-1 and mitochondrial AIF release. Thus, the PARP-1-generated death signal operates in both death pathways, although the pathways differ in substantial intermediary steps, such as the involvement of caspases.

An unanswered question is the potential role of $\mathrm{NAD}^{+}$depletion in PARP-1-mediated AIF release and cell death. Swanson and co-workers [38] suggested that both $\mathrm{NAD}^{+}$depletion and mitochondrial permeability transition are necessary in the cell death program leading from PARP-1 activation to AIF release and cell death in an astrocyte model using $100 \mu \mathrm{M}$ MNNG. These aspects as well as the evolutionary relationship of the PARP-1 signal relative to these pathways are now subject of further studies.

Acknowledgements. This work was supported by a grant from the Swiss National Foundation for scientific research awarded to F.R.A.

1 Ame, J. C., Spenlehauer, C. and de Murcia, G. (2004) The PARP superfamily. Bioessays 26, 882-893.

2 Schreiber, V., Dantzer, F., Ame, J. C. and de Murcia, G. (2006) Poly(ADP-ribose): novel functions for an old molecule. Nat. Rev. Mol. Cell. Biol. 7, 517-528.

3 Althaus, F. R., Kleczkowska, H. E., Malanga, M., Muntener, C. R., Pleschke, J. M., Ebner, M. and Auer, B. (1999) Poly ADPribosylation: A DNA break signal mechanism. Mol. Cell. Biochem. 193, 5-11.

4 D'Amours, D., Desnoyers, S., D'Silva, I. and Poirier, G. G. (1999) Poly(ADP-ribosyl)ation reactions in the regulation of nuclear functions. Biochem. J. 342, 249-268.

5 Schreiber, V., Ame, J. C., Dolle, P., Schultz, I., Rinaldi, B., Fraulob, V., Menissier-de Murcia, J. and de Murcia, G. (2002) Poly(ADP-ribose) polymerase-2 (PARP-2) is required for efficient base excision DNA repair in association with PARP-1 and XRCC1. J. Biol. Chem. 277, 23028-23036.

6 Malanga, M. and Althaus, F. R. (2005) The role of poly(ADPribose) in the DNA damage signaling network. Biochem. Cell Biol. 83, 354-364.

7 Hassa, P. O., Haenni, S. S., Elser, M. and Hottiger, M. O. (2006) Nuclear ADP-ribosylation reactions in mammalian cells: Where are we today and where are we going? Microbiol. Mol. Biol. Rev. 70, 789-829.

8 Ferro, A. M., Minaga, T., Piper, W. N. and Kun, E. (1978) Analysis of larger than tetrameric poly(adenosine diphosphoribose) by a radioimmunoassay in nuclei separated in organic solvents. Biochim. Biophys. Acta 519, 291-305.

9 Hilz, H., Wielckens, K., Adamietz, P., Bredehorst, R. and Kreymeier, A. (1983) Functional aspects of mono- and poly(ADP-ribosyl)ation: Subcellular distribution and ADPribosyl turnover under conditions of repair and 'starvation'. Princess Takamatsu Symp. 13, 155-163.
10 Kreimeyer, A., Wielckens, K., Adamietz, P. and Hilz, H. (1984) DNA repair-associated ADP-ribosylation in vivo. Modification of histone $\mathrm{H} 1$ differs from that of the principal acceptor proteins. J. Biol. Chem. 259, 890-896.

11 Burkle, A. (2000) Poly(ADP-ribosyl)ation: A posttranslational protein modification linked with genome protection and mammalian longevity. Biogerontology 1, 41-46.

12 Menissier de Murcia, J., Ricoul, M., Tartier, L., Niedergang, C., Huber, A., Dantzer, F., Schreiber, V., Ame, J. C., Dierich, A., LeMeur, M., Sabatier, L., Chambon, P. and de Murcia, G. (2003) Functional interaction between PARP-1 and PARP-2 in chromosome stability and embryonic development in mouse. EMBO J. 22, 2255-63.

13 Kim, M. Y., Zhang, T. and Kraus, W. L. (2005) Poly(ADPribosyl)ation by PARP-1: 'PAR-laying' $\mathrm{NAD}^{+}$into a nuclear signal. Genes Dev. 19, 1951-1967.

14 Davidovic, L., Vodenicharov, M., Affar, E. B. and Poirier, G. G. (2001) Importance of poly(ADP-ribose) glycohydrolase in the control of poly(ADP-ribose) metabolism. Exp. Cell Res. 268, 7-13.

15 Bonicalzi, M. E., Haince, J. F., Droit, A. and Poirier, G. G. (2005) Regulation of poly(ADP-ribose) metabolism by poly(ADP-ribose) glycohydrolase: Where and when? Cell. Mol. Life Sci. 62, 739-750.

16 Brochu, G., Duchaine, C., Thibeault, L., Lagueux, J., Shah, G. M. and Poirier, G. G. (1994) Mode of action of poly(ADPribose) glycohydrolase. Biochim. Biophys. Acta 1219, 342350.

17 Meyer-Ficca, M. L., Meyer, R. G., Coyle, D. L., Jacobson, E. L. and Jacobson, M. K. (2004) Human poly(ADP-ribose) glycohydrolase is expressed in alternative splice variants yielding isoforms that localize to different cell compartments. Exp. Cell Res. 297, 521-532.

18 Koh, D. W., Lawler, A. M., Poitras, M. F., Sasaki, M., Wattler, S., Nehls, M. C., Stoger, T., Poirier, G. G., Dawson, V. L. and Dawson, T. M. (2004) Failure to degrade poly(ADP-ribose) causes increased sensitivity to cytotoxicity and early embryonic lethality. Proc. Natl. Acad. Sci. USA 101, 17699-17704.

19 Andrabi, S. A., Kim, N. S., Yu, S. W., Wang, H., Koh, D. W., Sasaki, M., Klaus, J. A., Otsuka, T., Zhang, Z., Koehler, R. C., Hurn, P. D., Poirier, G. G., Dawson, V. L. and Dawson, T. M. (2006) Poly(ADP-ribose) (PAR) polymer is a death signal. Proc. Natl. Acad. Sci. USA 103, 18308-18313.

20 Yu, S. W., Andrabi, S. A., Wang, H., Kim, N. S., Poirier, G. G., Dawson, T. M. and Dawson, V. L. (2006) Apoptosis-inducing factor mediates poly(ADP-ribose) (PAR) polymer-induced cell death. Proc. Natl. Acad. Sci. USA 103, 18314-18319.

21 Yu, S. W., Wang, H., Poitras, M. F., Coombs, C., Bowers, W. J., Federoff, H. J., Poirier, G. G., Dawson, T. M. and Dawson, V. L. (2002) Mediation of poly(ADP-ribose) polymerase-1-dependent cell death by apoptosis-inducing factor. Science 297, 259263.

22 Susin, S. A., Lorenzo, H. K., Zamzami, N., Marzo, I., Snow, B. E., Brothers, G. M., Mangion, J., Jacotot, E., Costantini, P., Loeffler, M., Larochette, N., Goodlett, D. R., Aebersold, R., Siderovski, D. P., Penninger, J. M. and Kroemer, G. (1999) Molecular characterization of mitochondrial apoptosis-inducing factor. Nature 397, 441-446.

23 Wyatt, M. D. and Pittman, D. L. (2006) Methylating agents and DNA repair responses: Methylated bases and sources of strand breaks. Chem. Res. Toxicol. 19, 1580-1594.

24 Elbashir, S. M., Martinez, J., Patkaniowska, A., Lendeckel, W. and Tuschl, T. (2001) Functional anatomy of siRNAs for mediating efficient RNAi in Drosophila melanogaster embryo lysate. EMBO J. 20, 6877-6888.

25 Brochu, G., Shah, G. M. and Poirier, G. G. (1994) Purification of poly(ADP-ribose) glycohydrolase and detection of its isoforms by a zymogram following one- or two-dimensional electrophoresis. Anal. Biochem. 218, 265-272.

26 Bradbury, D. A., Simmons, T. D., Slater, K. J. and Crouch, S. P. (2000) Measurement of the ADP:ATP ratio in human leukae- 
mic cell lines can be used as an indicator of cell viability, necrosis and apoptosis. J. Immunol. Methods 240, 79-92.

27 Fernandez-Vizarra, E., Lopez-Perez, M. J. and Enriquez, J. A (2002) Isolation of biogenetically competent mitochondria from mammalian tissues and cultured cells. Methods 26, 292 297.

28 Lowry, O. H., Rosebrough, N. J., Farr, A. L. and Randall, R. J. (1951) Protein measurement with the Folin phenol reagent. J. Biol. Chem. 193, 265-275.

29 Ivana Scovassi, A. and Diederich, M. (2004) Modulation of poly(ADP-ribosylation) in apoptotic cells. Biochem. Pharmacol. 68, 1041-1047.

30 Blenn, C., Althaus, F. R. and Malanga, M. (2006) Poly(ADPribose) glycohydrolase silencing protects against $\mathrm{H}_{2} \mathrm{O}_{2}$-induced cell death. Biochem. J. 396, 419-429.

31 Tsujimoto, Y. (1997) Apoptosis and necrosis: Intracellular ATP level as a determinant for cell death modes. Cell Death Differ. 4, 429-434.

32 Moubarak, R. S., Yuste, V. J., Artus, C., Bouharrour, A., Greer, P. A., Menissier-de Murcia, J. and Susin, S. A. (2007) Sequential activation of poly(ADP-ribose) polymerase-1, calpains, and bax is essential in apoptosis-inducing factor-mediated programmed necrosis. Mol. Cell. Biol. 27, 4844-4862.
33 Winstall, E., Affar, E. B., Shah, R., Bourassa, S., Scovassi, A. I. and Poirier, G. G. (1999) Poly(ADP-ribose) glycohydrolase is present and active in mammalian cells as a $110-\mathrm{kDa}$ protein. Exp. Cell Res. 246, 395-398.

34 Oka, S., Kato, J. and Moss, J. (2006) Identification and characterization of a mammalian 39-kDa poly(ADP-ribose) glycohydrolase. J Biol Chem. 281, 705-713.

35 Dawson, V. L. and Dawson, T. M. (2004) Deadly conversations: Nuclear-mitochondrial cross-talk. J. Bioenerg. Biomembr. 36, 287-294.

36 Alvarez-Gonzalez, R. and Jacobson, M. K. (1987) Characterization of polymers of adenosine diphosphate ribose generated in vitro and in vivo. Biochemistry 26, 3218-3224.

37 Kiehlbauch, C. C., Aboul-Ela, N., Jacobson, E. L., Ringer, D. P. and Jacobson, M. K. (1993) High resolution fractionation and characterization of ADP-ribose polymers. Anal. Biochem. 208, 26-34.

38 Alano, C. C., Ying, W. and Swanson, R. A. (2004) Poly(ADPribose) polymerase-1-mediated cell death in astrocytes requires $\mathrm{NAD}^{+}$depletion and mitochondrial permeability transition. J. Biol. Chem. 279, 18895-18902.

\section{To access this journal online: http://www.birkhauser.ch/CMLS}

